\title{
CONHECIMENTO SOBRE O CARAMUJO GIGANTE AFRICANO (ACHATINA FULICA, LINNAEUS, 1758) ENTRE ESTUDANTES DE UMA ESCOLA PÚBLICA NO MUNICÍPIO DE BLUMENAU SC.
}

\section{KNOWLEDGE ABOUT THE GIANT AFRICAN SNAIL (ACHATINA FULICA, LINNAEUS, 1758) AMONG STUDENTS OF A PUBLIC SCHOOL IN THE CITY OF BLUMENAU SC.}

\author{
Suelen Cristina Grott ${ }^{1}$, Leônidas João de Mello ${ }^{2}$. \\ ${ }^{1}$ Programa de Pós Graduação em Engenharia Ambiental - FURB, suelengtt@ bol.com.br; \\ ${ }^{2}$ Instituto Federal de Santa Catarina, IFSC leonidas.junior@ifsc.edu.br;
}

\begin{abstract}
RESUMO
Achatina fulica Bowdich, 1822, espécie de molusco tropical africano, foi introduzida no Brasil em 1988 em substituição ao caramujo europeu Helix sp. - o escargot. Contudo, seu cultivo foi abandonado e o molusco transformou-se numa espécie invasora, registrada em 24 estados brasileiros. O município de Blumenau, SC, assim como diversos outros, apresenta problemas de invasão do caramujo africano, principalmente em áreas urbanas. Diante disso, o objetivo deste estudo foi avaliar o grau de conhecimento dos alunos da Escola Básica Municipal Professor Rodolfo Hollenweger, Blumenau-SC, bairro esse com o maior número de focos registrados da espécie no ano de 2011. Os dados foram obtidos através de um questionário, contendo dez perguntas. Observou-se que os estudantes possuem pouco conhecimento sobre a espécie e que desconhecem os métodos de controle, alimentação, doenças transmitidas e os impactos ambientais. Propõe-se que este conhecimento prévio seja levado em consideração na elaboração e execução de estratégias educativas que visem à conservação da natureza e o manejo de espécies exóticas.
\end{abstract}

Palavras-chave: Molusco terrestre, estudantes, conhecimento local, espécie invasora.

\begin{abstract}
Achatina fulica Bowdich, 1822 species of tropical African snail was introduced in Brazil in 1988 to replace the European snail Helix sp. - the escargot. However, its cultivation was abandoned and the mollusk has become an invasive species recorded in 24 Brazilian states. The city of Blumenau, SC, as well as several others, has problems of invasion of the african giant snail, mainly in urban areas. Thus, the aim of this study was to evaluate the degree of students' knowledge of the Municipal School Teacher Rodolfo Hollenweger, Blumenau-SC, and this district with the largest number of outbreaks of the species in 2011. Data were obtained through a questionnaire containing ten questions. It was observed that students have little knowledge about the species and are unaware of the methods of control, power transmitted diseases and environmental impacts. It is proposed that this prior knowledge is taken into account in the design and implementation of educational strategies aimed at nature conservation and management of exotic species.
\end{abstract}

Key words: Terrestrial mollusk, students, local knowledge, invasive species. 


\section{INTRODUÇÃO}

A introdução de espécies exóticas é considerada a segunda maior causa de extinção de espécies, o que afeta diretamente a biodiversidade (CORADIN \& TORTATO, 2006). A espécie Achatina fulica Bowdich, 1822 (Achatinidae), chamada popularmente de caramujo gigante africano (Figura 1), uma espécie exótica conhecida mundialmente pelo seu poder invasor, tem sido introduzida em diversos países, inclusive no Brasil (RAUT \& BARKER, 2002). O caramujo africano é um molusco terrestre, nativo da região leste-nordeste da África (VASCONCELLOS \& PILE; 2001) e é reconhecida como uma das cem piores espécies invasoras no mundo (ALOWE et al., 2004).

Uma das formas de introdução da espécie no Brasil ocorreu no Estado do Paraná, na década de 1988, por meio de uma feira agropecuária para fins alimentares (TELES \& FONTES, 2002). Porém, sua aceitação foi baixa, o que levou os produtores a desativaram seus plantéis, gerando fuga ou liberação intencional de exemplares na natureza (VASCONCELLOS \& PILE, 2001). Outras formas de introdução são citadas por Janol et al., 2010, porém todas para sua utilização na culinária. Atualmente, no país, o caramujo africano pode ser encontrado em 24 dos 26 estados, (sem registro apenas no Acre e Amapá) e no Distrito Federal (THIENGO \& FERNANDEZ, 2010).

A. fulica é frequentemente encontrado em ambientes antrópizados em diferentes municípios brasileiros, o que leva a considerar a possibilidade que seu estabelecimento esteja associado a ambientes alterados (FISCHER \& COSTA, 2010). Diante disso sérios problemas ambientais podem surgir, principalmente pelo fato de não haver predadores conhecidos para A. fulica no Brasil, representando uma ameaça para os caramujos nativos. Isso ocorre principalmente com espécies de Megalobulimus sp., frequentemente confundidas com a espécie invasora e, erroneamente sacrificadas. Colley e Fischer (2009) relataram impactos à biodiversidade causados pela infestação de A. fulica, tanto decorrentes da competição por espaço e alimento com os moluscos nativos, quanto pela interferência na cadeia alimentar. 
Ensino, Saúde e Ambiente - V7 (2), p. 12-27, Ago. 2014

Figura 1 - Achatina fulica (caramujo-gigante africano) no município de Blumenau, SC.

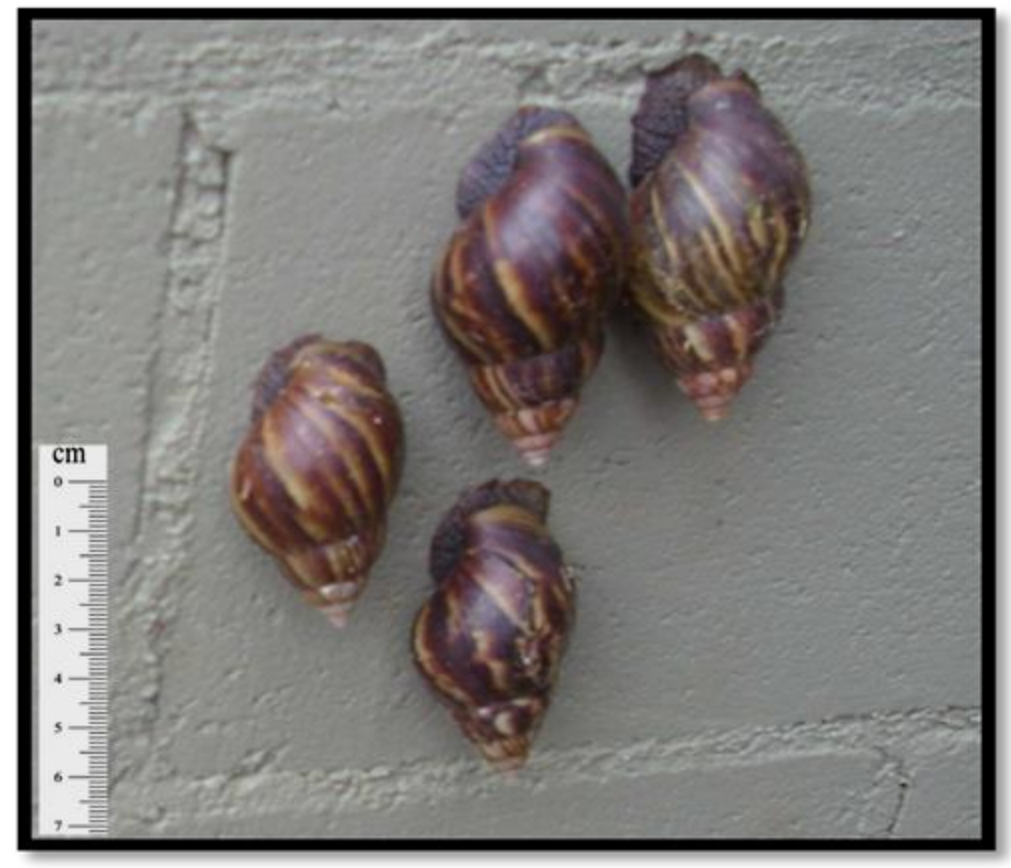

Fonte: Autores.

Em Santa Catarina, semelhante ao que ocorre em outros estados brasileiros, $A$. fulica está presente na maioria dos municípios, principalmente em áreas urbanas e periurbanas. Este fato tem sido constantemente noticiado pela mídia que enfatiza, de forma alarmante, o problema de saúde pública, relacionando diversas doenças ao caramujo africano, sem maior fundamentação técnica (SMS Florianópolis, 2010). Esta divulgação, aliada à presença do caramujo nas casas, causa preocupação entre alguns moradores das áreas afetadas. Verifica-se, no entanto, que a população é indiferente à resolução do problema. Segundo Fisher e Colley (2005), em um estudo na Ilha Rasa, Guaraqueçaba, PR, Brasil, poucos moradores se dispuseram a contribuir para o controle da espécie. Os autores consideram as características culturais e dificuldade de descartar o lixo como os principais entraves para adesão da população ao controle do caramujo na região.

Além dos prejuízos econômicos e ao ambiente, as densas populações de A. fulica em vida livre apresentam importância para a saúde pública por se tratar de uma espécie envolvida na transmissão de zoonoses. Os nematódeos Angiostrongylus cantonensis (Chen, 1935) e Angiostrongylus costaricensis (Morera \& Céspodes, 1971), responsáveis pela ocorrência da angiostrogilíase, pode ter A. fulica como um dos seus principais hospedeiros (THIENGO \& FERNANDEZ, 2010). 


\section{Ensino, Saúde e Ambiente - V7 (2), p. 12-27, Ago. 2014}

No Brasil, larvas de A. cantonensis foram encontradas em A. fulica procedentes do Estado de São Paulo e casos de meningite em decorrência da infecção foram registrados nos Estados do Espírito Santo (CALDEIRA et al., 2007) e Pernambuco (LIMA et al., 2009). A infecção ocorre pelo contato direto do caramujo infectado ou através do consumo de vegetais contendo o muco produzido pelo molusco. As crianças são as mais atingidas (TELES et al., 2004).

Com isso, a proposta de trabalho enquadra-se nos fundamentos dos Parâmetros Curriculares Nacionais do Ensino Fundamental (BRASIL, 1996), sobretudo pela função da educação básica em criar condições para que os alunos aprendam conteúdos necessários à compreensão da realidade e que, a partir destes, possam participar das relações sociais, políticas e culturais. No caso específico do caramujo africano, é importante que os alunos compreendam a importância da introdução de espécies exóticas para o ambiente e para a saúde, tendo como referência o local onde vivem, visando a uma aproximação do conteúdo escolar com o cotidiano.

Considerando que a escola pode ser um ambiente propício para discutir as relações dos seres humanos com as demais espécies biológicas, bem como as conexões entre o conhecimento local e a ciência formal, este trabalho teve por objetivo avaliar o conhecimento de estudantes do $8^{\circ}$ ano numa escola municipal em Blumenau, Santa Catarina, sobre o molusco africano A. fulica,

\section{METODOLOGIA}

O presente estudo foi realizado no município de Blumenau, que possui uma área de $520 \mathrm{~km}^{2}$ e localizado na planície litorânea do sul do Brasil, no nordeste do Estado de Santa Catarina, numa altitude média de $21 \mathrm{~m}$. A área urbana da cidade ocupa 36,5\% do município, contra 63,5\%, da zona rural (Prefeitura Municipal de Blumenau, 2013).

O local escolhido foi o bairro Fidélis, pois nesta localização foi registrado o maior número de focos de caramujo africano no ano de 2011 (Vigilância Sanitária de Blumenau, 2011). Atualmente, o bairro abriga desde fábricas de grande porte, serrarias, galpões e pequenas confecções. A vegetação predominante é herbácea e arbustiva. Na área urbana do bairro são observadas pequenas hortas e uma pecuária pouco significativa, ambas as atividades de subsistência. Na área rural predomina maior atividade agrícola, especialmente a hortifruticulura (Prefeitura Municipal de Blumenau, 2013). 
Neste bairro localiza-se a Escola Básica Municipal Professor Rodolfo Hollenweger, escola participante da pesquisa, e como objeto de estudo foi aplicado um questionário semiestruturado aos estudantes, contendo dez perguntas sobre o conhecimento dos mesmos em relação ao A. fulica. As questões foram elaboradas de forma objetiva e apresentavam uma linguagem simples e clara de modo que não apresentassem dificuldades para serem respondidas (Anexo 1). A opção pelo uso de questionários teve o propósito de registrar o conhecimento e visões dos estudantes sobre diferentes aspectos e implicações relacionados à presença do caramujo africano. Foram utilizadas questões fechadas e abertas, permitindo que os alunos expressassem suas opiniões.

O público alvo foi constituído por estudantes da $8^{\circ}$ série do Ensino Fundamental II, todos os alunos do turno matutino e da mesma sala de aula, com faixa etária entre 13 e 16 anos, totalizando 28 pessoas consultadas.

Anteriormente a pesquisa, a Unidade Escolar recebeu a visita dos pesquisadores e os estudantes receberam o Termo de Consentimento Livre Esclarecido - TCLE para que os pais e/ou responsáveis autorizassem a participação dos alunos. A pesquisa foi realizada no dia 01/10/2011 e somente participaram da pesquisa os estudantes que entregaram o TCLE assinado aos pesquisadores.

Destaca-se que os estudantes ainda não haviam vivenciado em sala de aula os conteúdos didáticos de Biologia sobre o Filo Mollusca, conforme informado pela docente responsável pela turma. Entretanto, diversos deles residem em locais com focos ou próximos à ocorrência da espécie invasora. Para verificação do conhecimento dos alunos sobre A. fulica, foi realizada uma pesquisa exploratória quantitativa através de um levantamento de informações em campo (Unidade Escolar).

\section{RESULTADOS E DISCUSSÃO}

As respostas dos 28 participantes foram contabilizadas e como primeiro item pesquisado os estudantes foram questionados se conhecem ou já ouviram falar do caramujo gigante africano, sendo que $89,29 \%$ responderam que conhecem o molusco. Embora esse dado indique que exista uma parcela significativa dos estudantes com conhecimento, são necessárias medidas para atingir uma parcela maior desta população, pois os estudantes pesquisados moram no local de maior ocorrência do caramujo africano no ano de 2010, segundo informações da Vigilância Ambiental do município 
de Blumenau. Corrobora para esta assertiva, o estudo realizado por Teles et al., (2004), onde $91,1 \%$ das pessoas que participaram da pesquisa afirmaram que conhecem o caramujo africano, ainda que parte do estudo foi realizado em uma região de pouco infestação do município de Atibaia, SP.

No município de Blumenau em um estudo realizado por Kipper et al., (2008) os autores analisaram o conhecimento que os moradores do bairro Itoupava Central possuem sobre a existência e riscos do caramujo africano. Diante dos resultados os pesquisadores concluíram que das 198 pessoas entrevistadas 69,7\% apresentam conhecimento sobre o caramujo africano. Porem, nenhuma das pessoas entrevistadas soube responder qual era a doença transmitida pelo caramujo, nem mesmo o grau de patogenicidade da mesma. Portanto, uma vez que o animal esteja presente nas residências e quintais, os moradores não reconhecerão o risco de contaminação.

Como segunda pergunta os estudantes foram questionados se as residências onde vivem apresentam problemas com o A. fulica, sendo que $71,43 \%$ dos estudantes responderam positivamente. Isso indica que a infestação encontra-se distribuída em vários pontos do bairro. Essa informação é de grande relevância, pois demonstra a importância de programas de promoção em saúde, devido ao fato do caramujo africano ser tratado como problema ambiental e de saúde pública, assim como maior atenção das Unidades Escolares, que devem buscar formas de informar os estudantes sobre os problemas ocasionados com a presença do caramujo.

Como item seguinte pesquisado ( $3^{\mathrm{a}}$ questão), os estudantes foram questionados em que local de sua residência os mesmos verificavam a presença do caramujo gigante africano. Em 46,42\% das respostas, os estudantes afirmaram que veem o caramujo africano na horta de suas casas (Figura 2). Isso se deve ao fato do caramujo africano possuir uma alimentação extremamente generalista, podendo alimentar-se de mais de 500 espécies vegetais, diminuindo a disponibilidade de alimento para a fauna nativa, podendo haver alterações de paisagens naturais por consumo de biomassa verde, principalmente brotos e plantas jovens (ESTON et al., 2006). 
Figura 2: Locais com a presença de A. fulica, segundo estudantes da E.B.M. Professor Rodolfo

Hollenweger, Blumenau, SC.

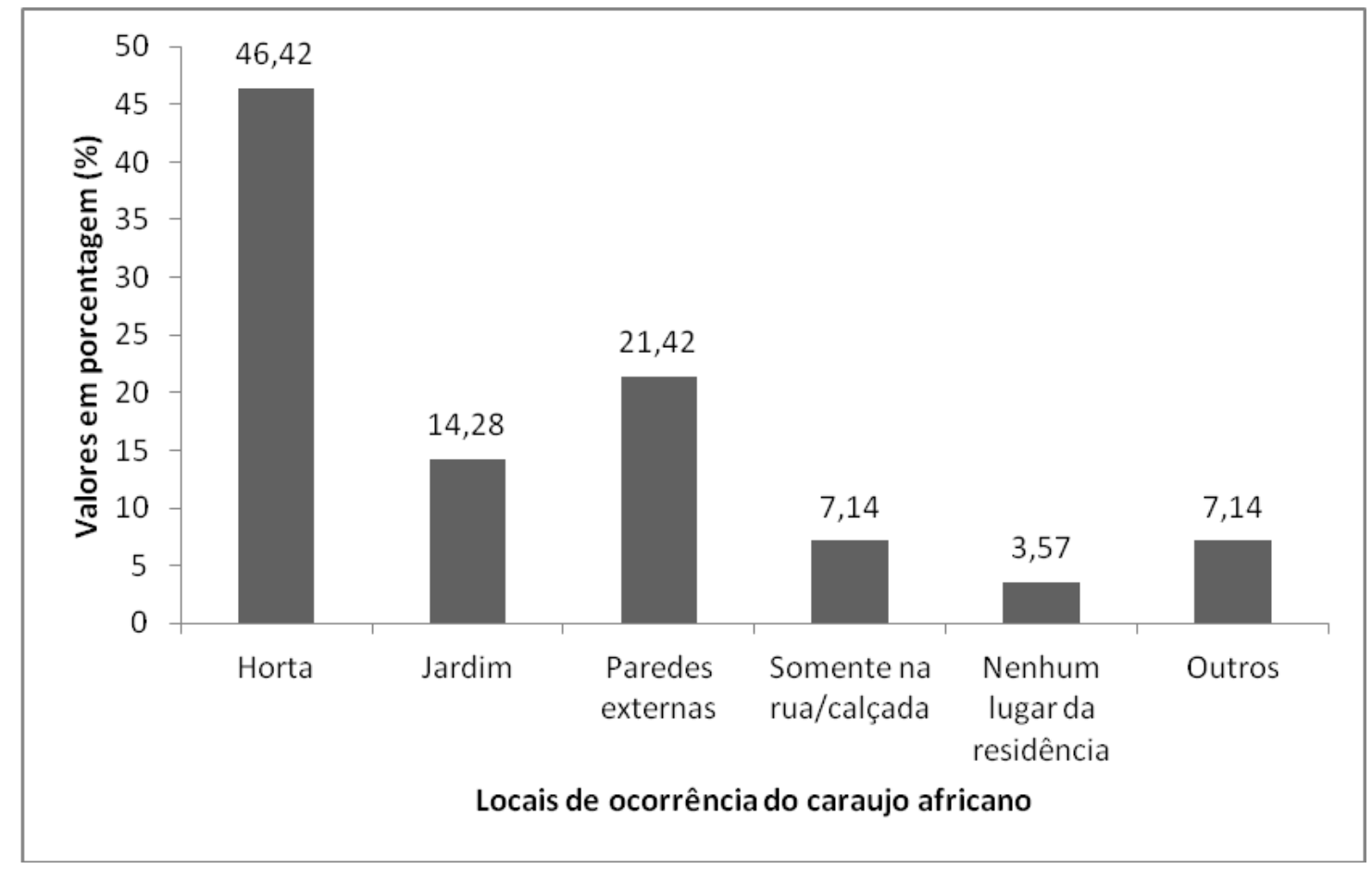

Fonte: Autores.

Como outros lugares onde foi verificada a presença de caramujo africano, os estudantes citaram paredes externas da residência, pastagens, a casa de vizinhos e áreas verdes. A expansão da agropecuária, especialmente, próxima às áreas naturais em bom estado de conservação, gerou um estreito vínculo entre as populações humanas, as de animais domésticos e as silvestres, "favorecendo a disseminação de agentes infecciosos e parasitários para novos hospedeiros e ambientes, estabelecendo-se assim novas relações entre hospedeiros e parasitas, e novos nichos ecológicos na cadeia de transmissão das doenças". (SILVA, 2013).

Os estudantes foram questionados em seguida ( $4^{\mathrm{a}}$ questão), sobre os hábitos alimentares do molusco. Como resultado, foi relatado que em 35,71\% os caramujos africanos foram vistos se alimentando de vegetação presente na residência ou nas proximidades, seguido de $17,85 \%$ que presenciaram se alimentando de frutos, $14,28 \%$ de lixo, 3,57\% de papelão e 28,57\% nunca viram os mesmos se alimentando. A utilização do lixo orgânico como fonte de alimento favorece a manutenção da espécie ao redor das residências. A presença de restos de comida e resíduos industriais, como papéis e isopor, em quintais e terrenos baldios, oferecerem substratos para A. fulica se abrigar e alimentar-se, favorecendo o estabelecimento dessa espécie em áreas urbanas. 
Em estudo sobre hábitos alimentares, Albuquerque et al., (2008) verificaram que o caramujo alimentou-se preferencialmente de plantas vasculares, porém os autores verificaram caramujos com hábitos saprófitos alimentando-se de fezes de equinos e bovinos.

Os moradores quando orientados sobre os métodos de coleta do caramujo, expõem as equipes da Secretaria de Saúde do município de Blumenau vários métodos que utilizam para eliminar os moluscos de suas residências, como, por exemplo, o uso de sal, a queima e o afogamento em balde com água. Diante disso, foi solicitado que os estudantes respondessem qual método é utilizado por sua família para eliminar os caramujos presentes em sua residência ( $5^{\text {a }}$ questão). Como alternativa mais citada pelos estudantes, o uso do sal correspondeu a 71,42\% das respostas (Figura 3). A forma de controle mais indicada pelo meio científico é a catação manual periódica dos animais e dos ovos, seguida de morte através da queima e destruição das conchas. Esta última ação evita o acúmulo de água que possibilitaria o desenvolvimento de larvas de mosquitos vetores de doenças (BARBOSA et al., 2002).

Figura 3: Métodos de extermínio do caramujo africano, segundo os estudantes E.B.M. Professor Rodolfo Hollenweger, Blumenau, SC.

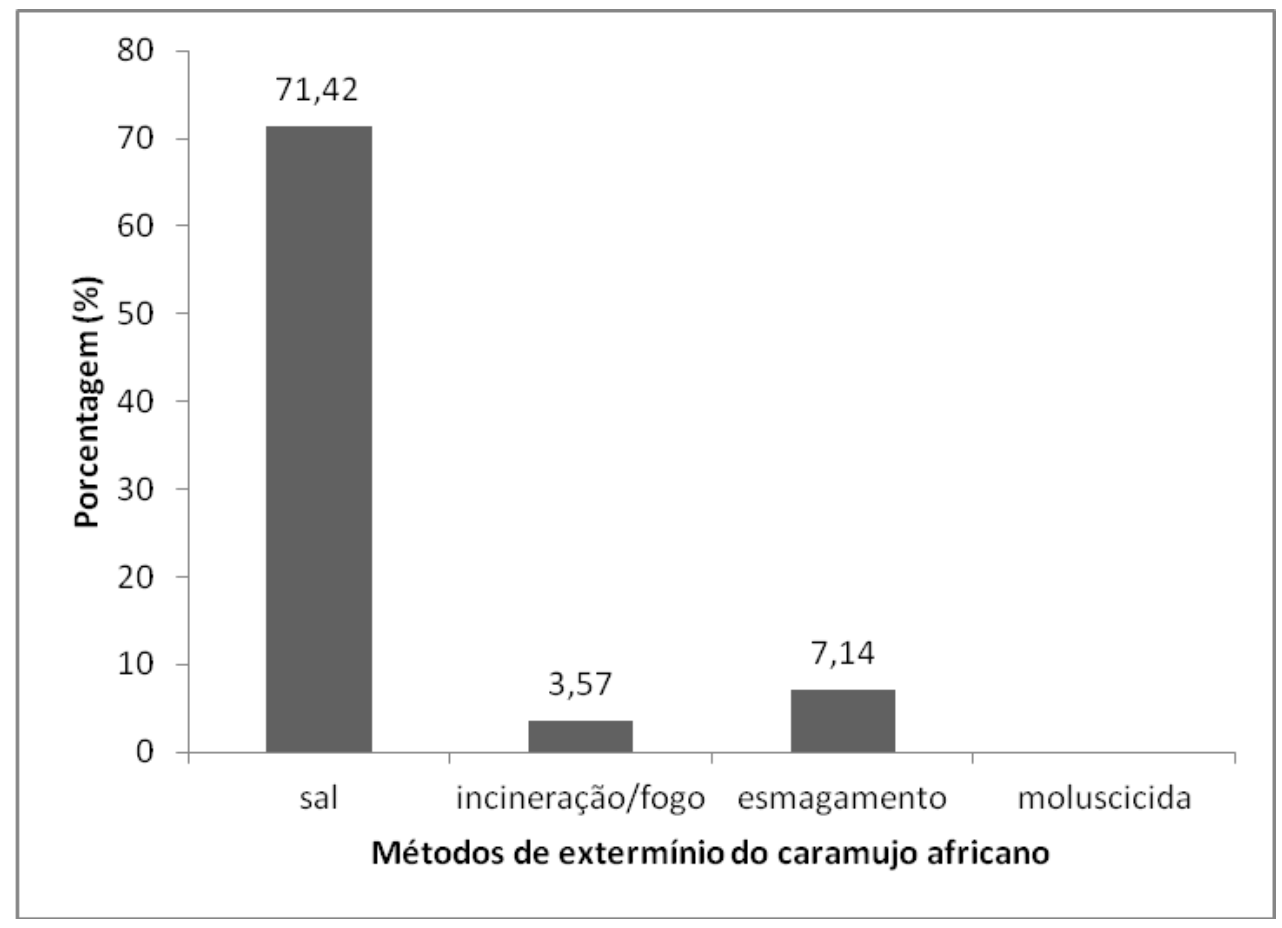

Fonte: Autores. 
Atualmente o controle de A. fulica realizado no Brasil baseia-se nas Instruções Normativas do IBAMA no 73, de 18 de agosto de 2005 (BRASIL, 2005) e n $^{\circ} 109$, de 3 de agosto de 2006 (BRASIL, 2006). Segundo estas instruções, o procedimento de controle do molusco consiste primeiramente na identificação da espécie em suspeita, evitando o extermínio de moluscos nativos. Após a identificação deve-se realizar o controle através da coleta manual do animal e de seus ovos, utilizando luvas e recipientes plásticos. Após a coleta os moluscos devem ser incinerados. Orienta-se a não utilização de sal, moluscicidas ou outros produtos tóxicos a outros animais. Métodos inadequados de descarte dos moluscos foram registrados como junto ao lixo doméstico ou em recursos hídricos. Tal prática traz grande preocupação, podendo colaborar para dispersão do animal (SIMIÃO \& FISHER, 2004; FISHER, 2009). Esta dispersão ocorre pela facilidade de sobrevivência do molusco em ambientes onde há depósito de lixo. Estudos conduzidos no Estado da Bahia comprovaram que A. fulica se instala preferencialmente em locais com intensa atividade humana, além de preferir terrenos mais sujos (ALBUQUERQUE et al., 2008).

Pode-se verificar que os estudantes não dão destino correto aos caramujos coletados nas residências, $60,71 \%$, (6 a questão) os mesmos convivem com o problema, mais não tentam solucioná-lo (Figura 4). Muitas vezes isso ocorre devido à falta de conhecimento a respeito do ciclo de vida dos caramujos africanos ou devido às baixas condições sanitárias presentes no bairro (Vigilância Ambiental de Blumenau, 2013). Quando questionados sobre as possíveis doenças transmitidas pelos moluscos, $100 \%$ dos estudantes responderam não saber seu nome ( $7^{a}$ questão). Da mesma forma, $100 \%$ das respostas foram negativas quando os estudantes foram indagados se há ou não vantagem na introdução da espécie como o caramujo africano em nossa cidade ( $8^{\mathrm{a}}$ questão). 
Figura 4: Destino dados pelos estudantes da E.B.M. Professor Rodolfo Hollenweger, Blumenau, SC aos exemplares de A. fulica.

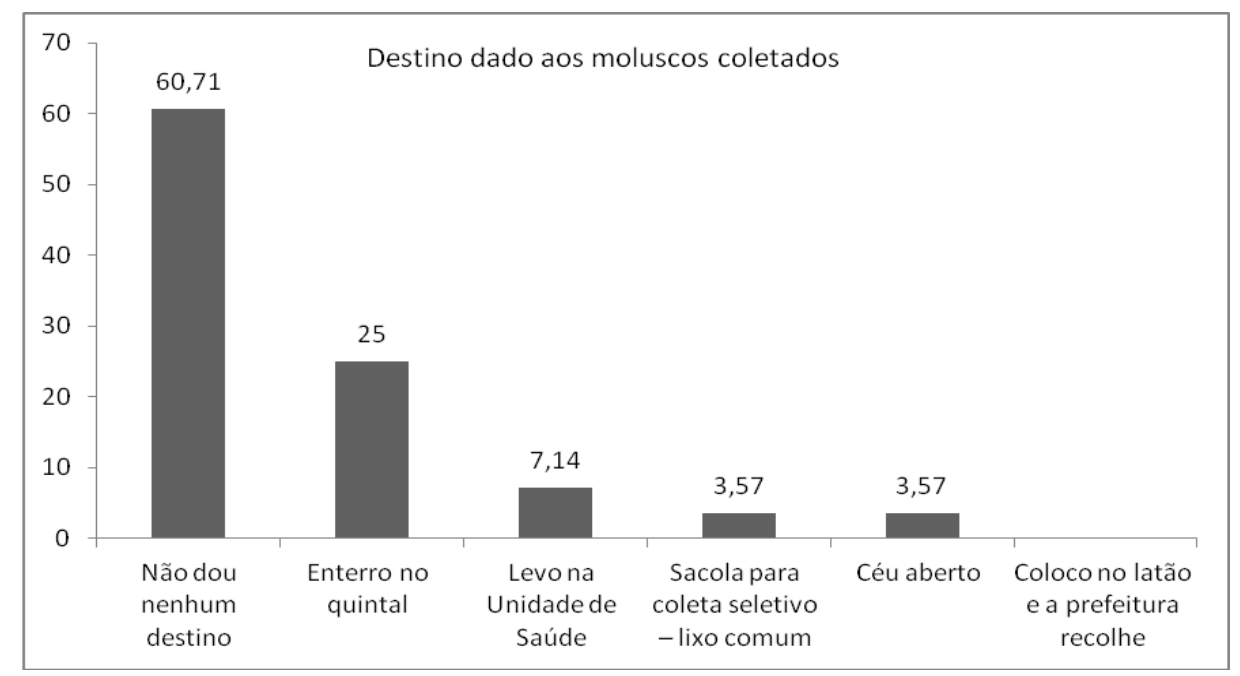

Fonte: Autores.

Simião e Fisher (2004) observaram em Pontal, Paraná, que os entrevistados não mostraram conhecimento da doença, relacionando o molusco a outras enfermidades como meningite, leishmaniose, alergias e doenças de pele. Colley e Fisher (2009) também observaram que nenhum dos entrevistados soube relacionar os verdadeiros problemas de saúde ocasionados pelo caramujo invasor, sendo citados: meningite, queimaduras, problemas respiratórios, cegueira, barriga d'água, câncer, manchas de pele, coceiras, febre, feridas e vômitos. Muito embora pesquisas apontem uma rejeição ao molusco por parte da população devido à possibilidade de transmissão de doenças, em geral os entrevistados não têm conhecimento sobre o ciclo de tais doenças (PEREIRA, 2010). Para a elaboração de estratégias eficientes de controle de A. fulica além do conhecimento sobre a espécie é importante o envolvimento das comunidades humanas afetadas pela presença do animal. Assim, é necessário investigar o conhecimento da população afetada sobre a proliferação do molusco e estratégias de controle utilizadas (SOUZA et al., 2007). Diante disso, os estudantes relataram o porquê avaliam como negativa a presença dos mesmos: "Porque eu não gosto de bicho desta espécie”; "Deve fazer mal”; "Não tem predadores então se multiplicam muito rápido" e "Porque eles são umas pragas".

Os estudantes sabem que os caramujos são espécies invasoras e que por algum motivo fazem mal a saúde, mais não conseguem analisar com clareza os principais problemas envolvidos na proliferação dos moluscos, pois mesmo que o risco de 


\section{Ensino, Saúde e Ambiente - V7 (2), p. 12-27, Ago. 2014}

transmissão de doenças ainda seja baixo, a proliferação desordenada do caramujo, causa sérios problemas ambientais.

Seguidamente foi solicitado aos estudantes que informassem se já assistiram a alguma palestra sobre o caramujo africano ( $9^{\text {a }}$ questão), sendo que $82,14 \%$ disseram nunca terem participado de uma ação educativa sobre o tema, nem na comunidade nem na escola. A Vigilância Ambiental do município realizou no ano de 2010 diversas ações educativas no bairro, entre elas: palestra aos moradores, mutirões de coleta, entrega de folder nas residências, distribuição e de latões nos ESF e posterior recolhimento dos caramujos coletados que foram incinerados no Aterro Municipal da cidade (Vigilância Ambiental de Blumenau, 2010).

Ao final do questionário ( $10^{\mathrm{a}}$ questão) foi solicitado que os estudantes expusessem o que em sua opinião deveria ser feito para que o caramujo africano fosse completamente eliminado do seu bairro. Deixou-se desta forma espaço para que os estudantes relacionassem alternativas ao controle do caramujo.

Pode-se perceber, em determinadas falas, que os estudantes conseguem avaliar a importância de manter suas residências limpas e organizadas: "Todos ajudarem a acabar com a espécie. Cada um cuidando de sua casa”; "Reonir (SIC) a comunidade para acabar com isso e levar a uma unidade de saúde”; "Que cada um cuide de sua casa”.

Porém, muitos estudantes apresentam informações equivocadas quanto aos procedimentos utilizados para eliminar os moluscos: "Jogando sal, matando ou esmagando e também queimando"; "Jogando sal e tocando fogo"; "Inventar algum veneno que mate eles".

Já em outras falas, pode-se perceber que os estudantes só buscam informações e tentam resolver os problemas quando os mesmos encontram-se próximos, ou seja, em suas residências: "Para mim e para minha família não causam problemas então não vejo o porquê de exterminar".

Em seguida pode-se perceber, em uma determinada fala, a omissão da na abordagem do tema, segundo o aluno: "Não sei, pq (SIC) eles nunca falaram na escola sobre caramujo africano". Portanto, verificou-se que certos discentes relacionam conteúdos vivenciados em sala de aula com experiências pessoais. Assim, os estudantes elencaram alternativas ao controle do caramujo africano: "Um grupo que entenda do assunto para combater essa praga"; "Na verdade quem deveria ter feito alguma coisa, foi quem trouxe achando que seria para comer"; "Orientar os moradores a melhor e 
mais segura forma de matá-los"; "Deveria passar alguem (SIC) recolhendo os caramujos".

Neste sentido, é importante levar em consideração o conhecimento prévio dos estudantes e suas conexões com outros saberes (inclusive a ciência formal), na elaboração e execução de ações educativas, visando aspectos como a saúde humana e a relação com espécies exóticas em diferentes contextos sociais e ecológicos. Segundo Oliveira et al., (2010), são necessárias ações de conscientização e educação ambiental. Há uma grande necessidade no controle de A. fulica, cuja situação no país foi de uma explosão populacional descontrolada cerca de dez anos após sua introdução, podendo acarretar no aumento das doenças que tenham essa espécie como transmissor (GRAEFF-TEIXEIRA, 2007).

Os Parâmetros Curriculares Nacionais são taxativos ao considerar a educação para a saúde um desafio a ser assumido em todos os níveis da educação no Brasil, da pré-escola à série terminal do ensino médio. Mas, ao defender a necessidade dessa abordagem, enfatizam, também, a importância de que a saúde seja tratada em suas múltiplas dimensões, individual e social, e de forma articulada (BRASIL, 1998).

Conforme os objetivos principais deste trabalho conclui-se que os estudantes não possuem conhecimento necessário para o controle da espécie, tanto em suas residências como no bairro onde residem. Os estudantes apresentaram informações errôneas e medidas habitualmente utilizadas pelos familiares, porém sem comprovação de sua real eficiência.

\section{AGRADECIMENTOS}

Os autores são gratos aos funcionários da Secretaria Municipal de Saúde, Vigilância Sanitária e Vigilância Ambiental de Blumenau pela atenção e informações disponibilizadas e pela liberação concedida ao primeiro autor para realização dessa pesquisa. E a coordenação do Instituto Federal de Santa Catarina pelo apoio e incentivo.

\section{REFERÊNCIAS BIBLIOGRÁFICAS}

ALBUQUERQUE, F. F.; PESO-AGUIAR, M. C.; ASSUNÇÃOALBUQUERQUE, M. J. T. Distribution, feeding behavior and control strategies of the exotic land snail 
Achatina fulica (Gastropoda: Pulmonata) in the northeast of Brazil. Brazilian Journal of Biology, v. 68, n. 4, p. 837-842, 2008.

ALOWE, S.; BROWNE, M.; BOUDJELAS, S. 100 of the worlds worst invasive alien species. A selection from the global invasive species database. 2004. Disponível em: <www.issg.org/database>. Acesso em: 21 set. 2013.

BARBOSA, A.; SALGADO; N.C., COELHO A.C.S.; MONTEIRO, J.C. Achatina fulica Bowdich, 1822, o "Caramujo Gigante Africano": história, biologia e controle de uma praga em expansão no Brasil (Mollusca, Gastropoda, Achatinoidea). O Biológico, v.64, n.1, p.115, 2002.

BRASIL, Secretaria de Educação Fundamental. Parâmetros Curriculares Nacionais. Terceiro e quarto ciclos do ensino fundamental: educação física. Brasília: Ministério da Educação/Secretaria de Educação Fundamental, 1996. 114p. (PCNs 5a a $8^{a}$ Séries).

BRASIL. Instrução Normativa $n^{\circ} 73$, de 18 de agosto de 2005. 2005. Disponível em: <www.cetesb.sp.gov.br/licenciamento/legislaçãofederal/inst_normativa/2005_instr_nor m_IBAMA>. Acesso em: 21 set. 2013.

BRASIL. Instituto Brasileiro do Meio Ambiente e dos Recursos Naturais Renováveis Parecer Técnico no 006/03- GGFAU Brasília. Brasília: IBAMA, 2006. 12 p.

CALDEIRA, R. L., MENDONÇA, C. L., GOVEIA, C.O., LENZI, H.L., GRAEFFTEIXEIRA, C., LIMA, W.S., MOTA, E.M., PECORA, I.L., MEDEIROS, A.M.Z. \& CARVALHO, O.S. First record of molluscs naturally infected with Angiostrongylus cantonensis (Chen, 1935) (Nematoda: Metastrongylidae) in Brazil. Memórias Instituto Oswaldo Cruz 102 (7): 887-889; 2007.

COLLEY, E, FISCHER, M.L. Avaliação dos problemas enfrentados no manejo do caramujo gigante africano Achatina fulica (Gastropoda: Pulmonata) no Brasil. Zoologia 26(4): 674-683; 2009.

CORADIN, L.; TORTATO, D. T. Espécies exóticas invasoras: situação brasileira. Brasília: Ministério do Meio Ambiente, Secretaria de Biodiversidade e Florestas, 2006. $24 \mathrm{p}$.

ESTON, M. R.; MENEZES, G. V.; ANTUNES, A. Z.; SANTOS, A. S. R.; SANTOS, A. M. R. Espécie invasora em unidade de conservação: Achatina fulica (Bowdich, 1822) no Parque Estadual Carlos Botelho, Sete Barras, SP, Brasil (Nota científica).

Revista do Instituto Florestal, São Paulo, vol. 18, n. único, p. 173-179, 2006.

FISCHER, M.L; COLLEY, E. Espécie invasora em reservas naturais: caracterização da população de Achatina fulica Bowdich, 1822 (Mollusca - Achatinidae) na Ilha Rasa, Guaraqueçaba, Paraná. Brasil. Biota Neotropica 5 (1): 2005.

FISCHER, M.L.; COSTA, L.C.M. O caramujo gigante africano Achatina fulica no Brasil. Editora Champagnat - PUCPR, Curitiba, p. 269, 2010. 
FISHER, M. L. Reactions of the invasive alien species Achatina fulica to abiotic factors: perspectives for the management. Revista Brasileira de Zoologia, Curitiba, v. 26, n. 3, p. 379-385, 2009.

GRAEFF-TEIXEIRA, C. Expansion of Achatina fulica in Brazil and potential increased risk for angiostrongyliasis. Transactions of the Royal Society of Tropical Medicine and Hygiene, London, v.101, p. 743-744, 2007.

ZANOL, J., FERNANDEZ, M. A., OLIVEIRA, A. P. M. \& THIENGO, S. C., The exotic invasive snail Achatina fulica (Stylommatophora, Mollusca) in the State of Rio de Janeiro (Brazil): current status. Biota Neotrópica, 10(3): 2010.

KIPPER, B.H. GIRARDI, P.; DESCHAMPS, S.; KUROKI, E.; STEIN, C.E. Perfil educativo sanitário em relação ao caramujo africano em uma área de incidência no Município de Blumenau - Santa Catarina. In: CONGRESSO BRASILEIRO DE MEDICINA VETERINÁRIA, 35, 2008, Gramado (RS). Anais... Rio Grande do Sul, 2008 .

LIMA, A.R.M.C., MESQUITA, S.D., SANTOS, S.S., AQUINO, E.R.P.D., ROSA, L.R.S., DUARTE, F.S., TEIXEIRA, A.O., COSTA, Z.R.S. \& FERREIRA, M. L. B. Alicata disease: neuroinfestation by Angiostrongylus cantonensis in Recife,

Pernambuco, Brazil. Arquivos de Neuro-Psiquiatria. 67 (4):1093-1096, 2009.

OLIVEIRA, A. P. M.; TORRES, E. J. L.; MALDONADO, A.; ARAÚJO, J. L. B.; FERNANDEZ, M. A.; THIENGO, S. C. Achatina fulica como hospedeiro intermediário de nematódeos de interesse médico-veterinário em Goiás, Brasil. Revista de Patologia Tropical, Goiania, v. 39, n. 3, p. 199-210, 2010.

PEREIRA, Z.M. Study of the perceptions of students from public network and helminthofauna associated with the African snail Achatina fulica Bowdich, 1822

(Mollusca, Gastropoda) in Barra the Piraí (RJ): support for an educational intervention. Dissertação de Mestrado. Instituto Oswaldo Cruz, Rio de Janeiro. 101pp, 2010.

PREFEITURA MUNICIPAL DE BLUMENAU. Disponível em: http://www.blumenau.sc.gov.br. Acesso em 05/out/2013.

RAUT S.K., BARKER G.M. Achatina fulica Bowdich and others Achatinidae pest in tropical agriculture In: BARKER, G. M. (Eds). Mollusks as croppest. New Zealand: CAB Publishing. 2002, p. 55-144.

Secretaria Municipal de Saúde de Blumenau - Vigilância Ambiental. Disponível em: <http://www.blumenau.sc.gov.br>. Acesso em 05/out/2013.

Secretaria Municipal de Saúde de Florianópolis. Boletim Informativo de controle do caramujo africano gigante. [online]; Disponível em:

<http://www.pmf.sc.gov.br/entidades/saude/. SMS, 2010>. Acesso em 18/set/2013

SILVA, Jean Carlos Ramos. Zoonoses e Doenças Emergentes Transmitidas por Animais Silvestres. Disponível em: 
<http://www.portaleducacao.com.br/veterinaria/artigos/2463/zoonoses-edoencas emergentes-transmitidas-por-animais-silvestres> Acesso em: 17 ago 2013.

SIMIÃO, M. S.; FISHER, M. L. Estimativa e inferência do método de controle do molusco exótico Achatina fulica Bowdich, 1822 (Stylommatophora; Achatinidae) em Pontal do Paraná, litoral do Estado do Paraná. Cadernos de Biodiversidade, Curitiba, v. 4, p. 74-83, 2004.

SOUZA, R. M.; ALVES, A. G. C.; ALVEZ, M. Z. Conhecimento sobre o molusco gigante africano Achatina fulica entre estudantes de uma escola pública na Região Metropolitana de Recife. Biotemas, Florianópolis, v. 20, p. 81-89, 2007.

TELES, H. M. S.; FONTES, L. R.; AMARAL, W. Pesquisa nacional de opinião pública sobre a espécie do caramujo Achatina fulica. Instituto Brasileiro de Helicicultura - Fundação CEDIC, Estância de Atibaia, 2004.

TELES H. M. S, FONTES L. R. Implicações da introdução e dispersão de Achatina fulica Bowdich, 1822 no Brasil. Boletim do Instituto Adolfo Lutz, v.12, n.1, p. 3-5, 2002.

THIENGO, S. C.; FERNANDEZ, M. A. Achatina fulica: um problema de saúde pública? In: FISCHER, M. L.; COSTA, L. C. M. (Eds). O caramujo gigante africano Achatina fulica no Brasil. Curitiba: Champagnat Editora - PUCPR, p. 189-202, 2010.

VASCONCELLOS, M. C.; PILE, E. Ocorrência de Achatina fulica no Vale do Paraíba, Estado do Rio de Janeiro, Brasil. Revista de Saúde Pública, São Paulo, v. 35, n. 6, p. 582-584, 2001.

\section{Anexo 1}

\section{LEVANTAMENTO DE INFORMAÇÕES SOBRE O CARAMUJO GIGANTE AFRICANO (Achatina fulica)}

Nome do entrevistado:

Endereço: N. ${ }^{\circ}$

Idade:

1. Você conhece e/ou já ouviu falar do caramujo gigante africano (Achatina fulica)?

( ) Sim ( )Não

2. Sua residência apresenta problemas com caramujo gigante africano (Achatina fulica)?

( ) Sim ( )Não

3. Em que local de sua residência você verifica a presença do caramujo gigante africano (Achatina fulica)?

( ) Horta ( ) Jardim ( ) Paredes externas ( ) Somente na rua/calçada ( )Nenhum local ( )Outros 
Quais:

4. Do que o caramujo gigante africano (Achatina fulica) se alimenta na sua residência? ( ) Vegetação ( ) Frutos ( )Lixo ( ) Papelão ( ) Nunca ví em minha casa ( ) Outros Quais:

5. Quais as medidas que você utiliza para o controle do caramujo gigante africano (Achatina fulica)?

( ) Sal ( ) Incineração-fogo ( ) Esmagamento ( ) Moluscicida ( ) Não uso nenhuma medida ( ) Outros

Quais:

6. Qual o destino dado para os caramujos e para as conchas do caramujo gigante africano (Achatina fulica)?

( ) Enterro no quintal ( ) Sacola para coleta seletivo - lixo comum ( ) Céu aberto

( ) Coloco no latão e a prefeitura recolhe ( ) Levo na Unidade de Saúde ( ) Não dou nenhum destino

( ) Outros

Quais:

7. Você sabe quais as doenças que podem ser transmitidas pelo caramujo gigante africano (Achatina fulica)?

( ) Sim ( )Não

Quais:

8. Você vê alguma vantagem na introdução de espécies exóticas como o caramujo africano?

( ) Sim ( )Não

Motivos:

9. Você já participou de alguma ação educativa (palestra) sobre o caramujo gigante africano (Achatina fulica)? ( ) Sim ( )Não

10. O que você acha que deveria ser feito para que o caramujo gigante africano (Achatina fulica) seja exterminado em seu bairro? 